\title{
Open Access Journals: What's the Problem?
}

\author{
Kenneth Nugent MD
}

The New England Journal of Medicine published four commentaries on open access publishing in the 02/28/2013 issue. These authors consider the recent changes in publication related to the development of the Internet, the cost associated with open access publishing, the legal issues relevant to open access publishing, and the potential downsides associated with this approach to the distribution of information. Ann Wolpert, MLS, noted that there is significant controversy and discussion related to open access, by which she meant unrestricted online access to articles published in scholarly journals. 'This activity has increased significantly over the last 10 years, and The Directory of Open Access Journals now lists more than 8000 journals. Some represent online expansions by traditional print publishers and some represent activities promoted and supported by institutions and organizations which have no prior history of print publications. Some appear to represent new business ventures by Internet entrepreneurs. Clearly, online publishing has created possibilities that would not exist if journals depended solely on print publishers, and our Journal would not be possible if we needed to find a print publisher. We make use of the Open Journal System, which is open software for the management of academic journals created by the Public Knowledge Project. It provides the technical infrastructure to manage all aspects of work flow and is currently used by more than 10,000 journals worldwide.

Martin Frank, PhD, discusses the cost of the academic publication and the potential approaches to open access. ${ }^{2}$ These include immediate open access, which is referred to as a gold open access, and green open access which usually involves an embargo. These approaches both have costs, and approximately $50 \%$ of journals now require an author fee. These fees may be paid by external grants, institutional funds, and/ or authors using their personal resources. Dr. Frank is worried that the diversion of money from research grants will ultimately reduce research activity. In addition, he notes that research intensive institutions with good external funding will likely pay a disproportionate share of the overall cost of open access. We think that most authors and their academic departments are willing to pay reasonable fees for publication. We also suggest that institutions have a lot to gain from the support of online journals. For example, health sciences centers could use academic publishing to support student and resident education, to support faculty development, and to support non-medical trainees in developing the technical skills necessary for work in information businesses and the editing skills necessary for technical writing. If these activities were integrated into class work and into the job expectations of faculty, costs would remain low, and the overall cost would represent a very small fraction of the entire budget of most health sciences centers in the United States.

Michael W. Carroll, JD, discusses potential application of copyright law to open access. ${ }^{3} \mathrm{He}$ describes six types of Creative Commons Licenses for original work. The most open license is the attribution license which allows others to distribute, translate, revise, and build on the author's work even for commercial applications so long as the individual making use of the work credits the author for the original creation. This seems very reasonable for most academic projects. The Internet allows for relatively easy misappropriation of others' work. Journals can try to prevent this but almost certainly will not be consistently successful. Therefore, maintaining copyright may be a hopeless task. In addition, we think that the collection of money based on the use of online work will not produce much income as most users will likely find the information they need through open and free sources. In our view we would be pleased to provide open use of any information published in our Journal.

Dr Charlotte Haug, MD, PhD, the editor of the Journal of the Norwegian Medical Association, 
discusses the potential downside of open access publishing. ${ }^{4}$ She is concerned that some journals will have laxeditorial and review processes and could represent "predatory publishers" which scam money out of authors with little effort from the journal. Obviously, publishing fraud is quite possible and potentially explains some of the recent increase in the number of open access journals. In the end she maintains that transparency is crucial to the individual journal and the entire industry. In our case we solicit articles from all interested parties, we provide peer review and assistance with copyediting, and we expect the articles to provide new information or useful reviews of the medical literature. The editors, reviewers, and authors are not paid anything. The production team is paid, but too little for their effort. We do not charge authors yet but expect to do so in the future. Please look at the content. We think we are meeting our goals.

Open access is here to stay. There are many potential winners.

\section{REFERENCES}

1. Wolpert AJ. For the Sake of Inquiry and Knowledge - The Inevitability of Open Access. N Engl J Med 2013; 368:785-86.

2. Frank M. Open but Not Free - Publishing in the 21st Century. N Engl J Med 2013; 368:787-789

3. Carroll MW. Creative Commons and the Openness of Open Access. N Engl J Med 2013; 368: 789-791.

4. Haug C. The Downside of Open-Access Publishing. N Engl $J$ Med 2013; 368:791-793.

Author Contact Information: kenneth.nugent@ttuhsc.edu DOI: 10.12746/swrccc2013.0102.012 